\title{
Acidification des sols ferrugineux et ferrallitiques dans les systèmes de production cotonnière au Burkina Faso
}

\author{
Bazoumana KOULIBALY ${ }^{1}$, Ouola TRAORE², Déhou DAKUO ${ }^{3}$, \\ Roland LALSAGA ${ }^{4}$, François LOMPO ${ }^{1}$ et Prosper N. ZOMBRE ${ }^{4 *}$ \\ ${ }^{1}$ Institut de l'Environnement et de Recherches Agricoles (INERA), 01 BP 7192 Ouagadougou 01, \\ Burkina Faso. \\ ${ }^{2}$ Union Economique et Monétaire Ouest africaine (UEMOA), Ouagadougou, Burkina Faso. \\ ${ }^{3}$ Société Burkinabé des Fibres Textiles (SOFITEX), Direction du Développement de la Production Cotonnière, \\ 01 BP 147, Bobo-Dioulasso 01, Burkina Faso. \\ ${ }^{4}$ Unité de Formation des Sciences de la Vie et de la Terre (UFR/SVT), Laboratoire de Biologie et Ecologie \\ Végétale, Université de Ouagadougou, 01 BP 7021 Ouagadougou 01, Burkina Faso. \\ *Auteur correspondant, E-mail: prosper.zombre@univ-ouaga.bf
}

\section{RESUME}

La productivité des systèmes de culture coton-céréales est menacée par la dégradation et l'acidification des terres. Afin de déterminer les causes de l'acidification des sols dans la zone cotonnière du Burkina Faso, une expérimentation a été conduite pendant deux années, en milieu paysan, sur des sols ferrugineux et ferrallitiques, respectivement sur les sites de Dohoun et Balla. Trois modes d'exploitation des terres, définis par la jachère, la culture attelée et la culture motorisée, ont été comparés pour déterminer leurs effets sur les caractéristiques physico-chimiques des sols étudiés. Par rapport à la jachère, comparée à la culture attelée, la culture motorisée a entraîné, en surface $(0-20 \mathrm{~cm})$ des sols ferrugineux et ferrallitiques, une augmentation des teneurs en sable de 8 à $12 \%$ et une baisse du taux d'argile de $35 \%$ qui expose ces sols à l'acidification. Contrairement à la jachère, la culture motorisée a entraîné des pertes significatives de carbone et d'azote, qui rendent les sols plus sensibles à l'acidification qu'en culture attelée. L'exploitation des terres s'est aussi traduite par une baisse significative des teneurs des cations majeurs du complexe adsorbant $\left(\mathrm{Ca}^{2+}\right.$ et $\mathrm{Mg}^{2+}$ ), de la somme des bases échangeables (SBE) et de la capacité d'échange cationique (CEC), accentuant la vulnérabilité à l'acidification sous culture motorisée. La dégradation des sols cultivés a été plus importante pour les sols ferrallitiques qu'au niveau des sols ferrugineux, dont la CEC a été 2 à 3 fois plus élevée. La culture attelée et la culture motorisée, pratiquées, le plus souvent, sans restitution organique, se sont révélées comme étant des causes de l'acidification des sols ferrallitiques, plus accentuée que celle des sols ferrugineux. L'étude recommande d'adopter des techniques adéquates de travail du sol et de procéder à des amendements appropriés pour atténuer l'acidification et garantir la durabilité des systèmes de production.

(C) 2014 International Formulae Group. All rights reserved.

Mots clés: Exploitation des terres, acidification, sol ferrugineux, sol ferrallitique, zone cotonnière.

\section{INTRODUCTION}

$\mathrm{Au}$ Burkina Faso, le coton est la principale culture de rente. Il constitue une importante source de revenu pour les producteurs, et de devises, pour le pays, avec plus de $60 \%$ des recettes d'exportation (Hauchart, 2006). La culture cotonnière est pratiquée sur des sols qui sont pour la plupart,

(C) 2014 International Formulae Group. All rights reserved.

DOI : http://dx.doi.org/10.4314/ijbcs.v8i6.44 
d'un faible niveau de fertilité, assez fragiles et sensibles à l'érosion. La dégradation de la fertilité des sols, généralement, observée dans les systèmes de culture à base de cotonnier et de céréales, affecte la productivité des cultures, avec notamment, une stagnation voire, une baisse des rendements en coton graine (Koulibaly et al., 2010). L'accroissement de la production cotonnière au Burkina Faso au cours de la dernière décennie, a été surtout lié à l'extension des superficies cultivées, ce qui n'est pas envisageable sur le long terme, compte tenu de la démographie galopante qui accentue la pression sur le foncier (Traoré et al., 2007; Pouya et al., 2013).

Le développement de la culture cotonnière a été le moteur de l'équipement des exploitations en matériels de traction attelée ou motorisée (Mbétid-Bessane, 2010). La motorisation des exploitations cotonnières s'est faite avec, souvent, l'utilisation d'outils de travail du sol inadaptés, ce qui favorise davantage l'accroissement des surfaces cultivées plutôt que l'intensification de la production (Barro et al., 2009; Pouya et al., 2013). Dans ce contexte, la dégradation des ressources naturelles, et la baisse de la fertilité des sols, liées à des pratiques culturales extensives, tendent à compromettre la durabilité des systèmes de production, à cause de l'acidification qui en résulte (Agoumé et Birang, 2009; Schroder et al., 2011). Toute surexploitation des terres se traduit par une baisse de la teneur en matière organique, une dégradation de la structure du sol, favorisant l'érosion, et la baisse du $\mathrm{pH}$; ce qui diminue davantage la capacité de ces terres à produire (Sawadogo et al., 2008; Pallo et al., 2009).

L'acidification des sols cultivés est l'une des causes de la baisse des rendements des cultures, notamment ceux du cotonnier, sensible à la réaction du sol (Brady et Weil, 2008). Dans la zone cotonnière ouest du Burkina Faso, une faible efficience des engrais minéraux sur les rendements a été observée sur des sols acides. Dès lors, un diagnostic des causes de l'acidification des sols s'avère indispensable. La présente étude vise à déterminer les raisons de l'acidification des sols ferrugineux et ferrallitiques, qui sont les deux principaux types de sol cultivés en zone cotonnière. Les modes d'exploitation des terres sont alors analysés pour évaluer leurs effets sur l'acidification des sols et ses conséquences sur la durabilité des systèmes de culture coton-céréales.

\section{MATERIEL ET METHODES \\ Sites d'étude}

L'étude a été conduite pendant deux années, en 2006 et 2007, sur les sites de Dohoun et de Balla, qui sont situés dans la zone cotonnière Ouest du Burkina Faso, limitée, au Nord, par l'isohyète 700 mm et, au Sud, par l'isohyète $1000 \mathrm{~mm}$ (Barro et al., 2009). Le climat est du type sud-soudanien, avec une saison pluvieuse allant de mai à octobre, et une saison sèche, de novembre à avril. Le site de Dohoun a pour coordonnées géographiques $11^{\circ} 31^{\prime}$ '549', de latitude Nord, $3^{\circ} 36^{\prime}$ '263' ' de longitude Ouest et 327,3 m d'altitude. Les sols, de type ferrugineux tropical lessivé, sont issus de l'altération de cuirasses ferrugineuses latéritiques, riches en sesquioxydes de fer et d'alumine (Koulibaly, 2011). A Dohoun, la pluviométrie en 2006 et 2007 était, respectivement, de 937 et 1022 $\mathrm{mm}$, sur 63 et 46 jours de pluie. Sur le site de Balla (11 ${ }^{\circ} 29^{\prime}$ '902', de latitude Nord, $4^{\circ} 07^{\prime}$ 088' de longitude Ouest et $315 \mathrm{~m}$ d'altitude), les sols ferrallitiques sont formés à partir de matériaux gréseux, avec de faibles teneurs en oxydes d'aluminium et de fer. La pluviométrie à Balla était respectivement, 1084 et 754 mm en 2006 et 2007, sur 49 et 31 jours de pluie.

\section{Facteurs étudiés}

L'étude a été réalisée sur deux types de sol prédominants dans la zone cotonnière du Burkina Faso. Il s'agit des sols ferrugineux 
tropicaux lessivés (CPCS, 1967) ou lixisols (FAO, 2006), pour le site de Dohoun, et des sols ferrallitiques faiblement désaturés sur matériaux sableux (CPCS, 1967) ou ferralsols (FAO, 2006), pour le site de Balla. Sur ces deux types de sol, généralement cultivés et rarement sous jachère, trois modes d'exploitation des terres ont été comparés et définis ainsi qu'il suit :

\section{Sols sous jachère naturelle}

Parcelles mises en jachère pendant 10 à 15 années, sans aucune introduction d'espèce végétale améliorante. Les jachères occupent d'assez faibles superficies et sont parfois pâturées ;

\section{Sols sous culture attelée}

Parcelles sous exploitation continue durant 20 à 30 années, avec utilisation de la traction bovine pour la préparation du sol, les opérations de désherbage et de buttage. Le système de culture est basé sur des rotations coton-céréales; les céréales étant souvent associées à l'arachide et au niébé. Les herbicides sélectifs et non sélectifs, les insecticides à base de pyréthrinoïdes et d'organophosphorés, ainsi que les engrais minéraux sont utilisés pour la production du coton et du maïs. Les autres cultures (sorgho, légumineuses et sésame) ne sont généralement pas fertilisées.

\section{Sols sous culture motorisée}

Parcelles mises en culture continue pendant 15 à 30 années. Les opérations de travail du sol y sont réalisées avec des tracteurs dont la puissance varie entre 40 et 60 $\mathrm{CV}$. Le désherbage et le buttage sont assurés par la traction bovine. L'utilisation des intrants (herbicides, insecticides et engrais minéraux) y est plus forte.

\section{Modalités de prélèvements des sols}

Une enquête préalable a été réalisée sur le passé cultural des exploitations sur les deux sites d'étude, en 2006. Pour chacun des trois modes d'exploitation des terres étudiés (sols sous jachère, sols sous culture attelée et sols sous culture motorisée), six parcelles ont été retenues comme répétitions, soit un total de 36 parcelles, dont 18 sur sols ferrugineux et 18 sur sols ferrallitiques. En 2006, 72 échantillons de sol ont été prélevés, à la tarière, dans ces 36 parcelles, aux profondeurs de $0-20 \mathrm{~cm}$ et $20-40 \mathrm{~cm}$. Ces prélèvements à la tarière ont été effectués suivant les diagonales des parcelles, en six points, distants d'au moins 60 mètres. Les sols ainsi prélevés, selon les différents niveaux de profondeur, ont été mélangés pour constituer des échantillons composites. En 2007, sur les 36 parcelles initialement retenues, 18 fosses pédologiques ont été ouvertes, selon les normes du Bureau National des Sols du Burkina Faso (Bunasols, 1987), sur la base de trois répétitions pour chacun des modes d'exploitation des terres, ce qui représente 9 fosses sur sols ferrugineux (Dohoun) et 9 fosses sur sols ferrallitiques (Balla). Au total, 36 échantillons de sol ont été prélevés dans ces fosses pédologiques, aux profondeurs de $0-20 \mathrm{~cm}$ et $20-40 \mathrm{~cm}$. Tous les échantillons de sol prélevés à la tarière et dans les fosses pédologiques ont été séchés à l'air, puis tamisés à $2 \mathrm{~mm}$, pour les analyses en laboratoire.

\section{Paramètres déterminés}

Les caractéristiques physico-chimiques des échantillons de sols prélevés ont été déterminées au laboratoire du Bureau National des Sols du Burkina Faso. Pour l'analyse granulométrique du sol à 3 fractions, la méthode à la Pipette de Robinson Köln a été utilisée. Le carbone organique est déterminé par la méthode Walkley et Black (1934) et l'azote total par minéralisation de Kjeldahl. Les bases échangeables ont été déterminées par dosage spectrométrique des cations $\mathrm{Ca}^{2+}$ et $\mathrm{Mg}^{2+}$ en absorption atomique, puis de $\mathrm{Na}^{+}$et $\mathrm{K}^{+}$en 
émission de flamme. La capacité d'échange cationique (CEC) a été mesurée à partir de la solution d'extraction des bases échangeables. Le $\mathrm{pH}$ eau et le $\mathrm{pH} \mathrm{KCl}$ du sol ont été déterminés par lecture directe au $\mathrm{pH}$-mètre à électrode en verre, selon un rapport sol/solution de $1 / 2,5$ et après un temps d'équilibre de 4 heures de l'eau et du $\mathrm{KCl}$ (McLean, 1982).

\section{Analyses statistiques des données}

Les données collectées ont été soumises à une analyse de variance avec logiciel XLSTAT 2007. Le test de Fisher a été utilisé pour la séparation des moyennes lorsque l'analyse de variance révèle des différences significatives entre les traitements au seuil de probabilité de 5\%.

\section{RESULTATS}

Incidence des modes d'exploitation des terres sur la composition granulométrique des sols

Sur les sols ferrugineux de Dohoun et les sols ferrallitiques de Balla, les fractions granulométriques les plus importantes sont les sables, éléments grossiers, suivis des limons (Tableau 1). Par rapport aux sols sous jachère, il a été noté, sous la culture motorisée, une baisse significative de la teneur en argile ( $\mathrm{p}=$ $0,046)$ et une augmentation de la teneur en sable de $12 \%$, dans la couche $0-20 \mathrm{~cm}$ des sols ferrugineux. Dans les sols ferrallitiques et sur la profondeur $0-20 \mathrm{~cm}$, par rapport aux teneurs observées sous la culture attelée, la teneur d'argile a baissé de $35 \%$, tandis que celle du sable a augmenté, de façon significative, de $8 \%$, sous la culture motorisée. Le Tableau 1 fait ressortir que par rapport aux sols ferrugineux, les sols ferrallitiques ont de plus faibles teneurs en argile, qui baissent davantage sous culture motorisée.

\section{Modification des caractéristiques chimiques des sols et acidification sous l'exploitation des terres \\ Modification des teneurs en carbone et en azote des sols}

Les Figures 1 et 2 montrent que les teneurs en carbone et en azote des sols ferrugineux sont deux fois plus élevées que celles des sols ferrallitiques. Dans les sols ferrugineux, les teneurs en carbone et en azote étaient statistiquement équivalentes sous la jachère et sous la culture attelée, en surface $(0-20 \mathrm{~cm})$, alors qu'elles ont baissé de façon significative sous la culture motorisée, tant en surface qu'en profondeur (Figures 1a et 2a). Par rapport aux sols sous culture attelée, comparés à ceux sous jachère, les teneurs en carbone et en azote ont baissé, respectivement, de $50 \%$ et $21 \%$, sur $0-20 \mathrm{~cm}$ et $20-40 \mathrm{~cm}$. Dans les sols ferrallitiques, bien que les teneurs en carbone et en azote soient statistiquement homogènes, ces deux éléments ont baissé d'environ 25\%, sous culture motorisée comparativement aux sols sous jachère naturelle (Figures $1 \mathrm{~b}$ et $2 \mathrm{~b}$ ). Ces diminutions de teneurs de carbone et d'azote, induites par la culture motorisée, exposent davantage le sol à l'acidification par rapport à la culture attelée.

Incidence de l'exploitation des terres sur la modification de la valeur des bases échangeables et de la capacité d'échange cationique des sols

Par rapport à la jachère, la mise en culture des sols ferrugineux et ferrallitiques a significativement influencé les teneurs des cations majeurs du complexe adsorbant $\left(\mathrm{Ca}^{2+}\right.$ et $\mathrm{Mg}^{2+}$ ) ainsi que la somme des bases échangeables (SBE) (Tableau 2). Dans ces deux types de sols, la culture motorisée a engendré les plus faibles réserves en $\mathrm{Ca}^{2+}$ et $\mathrm{Mg}^{2+}$, dont les teneurs ont été significativement inférieures $(\mathrm{p}=0,036)$ aux teneurs des sols sous jachère, comparés aux 
sols sous culture attelée. Pour les sols ferrugineux, la SBE qui était 2 à 3 fois plus élevée sous la jachère, a baissé de façon significative dans les sols sous culture attelée et sous culture motorisée (Tableau 2). Par rapport aux sols ferrallitiques sous jachère et sous culture attelée, la SBE a baissé davantage sous la culture motorisée, ce qui réduit la fertilité chimique du sol (Tableau 2). Les valeurs de la CEC des sols ferrugineux ont été 2 à 3 fois supérieures à celles des sols ferrallitiques. Ces valeurs décroissent davantage sous la culture motorisée, par rapport à la culture attelée et à la jachère, et entraînent une baisse significative de la CEC des sols ferrugineux $(\mathrm{p}=0,006)$.

Incidence des modes d'exploitation des terres sur la réaction des sols

Comparativement à la jachère et à la culture attelée, la culture motorisée a entraîné une baisse du $\mathrm{pH}$ eau et du $\mathrm{pH} \mathrm{KCl}$ des sols ferrugineux et ferrallitiques (Tableau 3). Dans les sols ferrugineux, tout comme au niveau des sols ferrallitiques, les valeurs des $\mathrm{pH} \mathrm{KCl}$ (sur $0-20 \mathrm{~cm}$ ) sous culture motorisée, étaient significativement inférieures à celles des sols sous jachère et sous culture attelée. Par rapport à cette couche de surface, on observe une augmentation sensible de l'acidification des sols ferrallitiques en profondeur, sur 20-40 cm (Tableau 3).

Aussi bien dans les sols ferrugineux de Dohoun que dans les sols ferrallitiques de Balla, les teneurs en aluminium échangeable étaient très faibles et n'ont pas été influencées, ni par la nature du sol ( $\mathrm{p}=0,728)$, ni par les modes d'exploitation des terres $(p=0,726)$ (Tableau 4). Dans ces sols, l'on a noté de très faibles concentrations d'aluminium échangeable qui, pourtant, contribuent, pour près de $75 \%$, aux variations de l'acidité totale.

Tableau 1 : Composition granulométrique des sols.

\begin{tabular}{|c|c|c|c|c|c|}
\hline Types de sol & Couches & $\begin{array}{l}\text { Modes d'exploitation des } \\
\text { terres }\end{array}$ & Argile & $\frac{\text { Limons }}{\mathrm{g} \mathrm{kg}^{-1}}$ & Sables \\
\hline \multirow{8}{*}{$\begin{array}{l}\text { Ferrugineux } \\
\text { (site de Dohoun) }\end{array}$} & \multirow{4}{*}{$0-20 \mathrm{~cm}$} & Sols sous jachère & $150,17^{\mathrm{a}}$ & $347,77^{\mathrm{a}}$ & $502,40^{\mathrm{a}}$ \\
\hline & & Sols sous culture attelée & $144,25^{a b}$ & $399,05^{\mathrm{a}}$ & $456,70^{\mathrm{a}}$ \\
\hline & & Sols sous culture motorisée & $97,57^{\mathrm{b}}$ & $339,75^{a}$ & $562,70^{a}$ \\
\hline & & Probabilité (5\%) & 0,046 & 0,761 & $\mathbf{0 , 5 3 1}$ \\
\hline & \multirow{4}{*}{$20-40 \mathrm{~cm}$} & Sols sous jachère & $195,25^{\mathrm{a}}$ & $292,10^{\mathrm{a}}$ & $512,65^{\mathrm{a}}$ \\
\hline & & Sols sous culture attelée & $207,25^{a}$ & $369,60^{\mathrm{a}}$ & $423,15^{\mathrm{a}}$ \\
\hline & & Sols sous culture motorisée & $167,17^{\mathrm{a}}$ & $428,33^{\mathrm{a}}$ & $404,50^{\mathrm{a}}$ \\
\hline & & Probabilité (5\%) & $\mathbf{0 , 3 8 9}$ & $\mathbf{0 , 2 2 8}$ & 0,454 \\
\hline \multirow{8}{*}{$\begin{array}{l}\text { Ferrallitiques } \\
\text { (site de Balla) }\end{array}$} & \multirow{4}{*}{$0-20 \mathrm{~cm}$} & Sols sous jachère & $137,08^{a}$ & $109,48^{b}$ & $753,70^{\mathrm{ab}}$ \\
\hline & & Sols sous culture attelée & $149,45^{\mathrm{a}}$ & $140,33^{\mathrm{a}}$ & $712,73^{b}$ \\
\hline & & Sols sous culture motorisée & $88,43^{a}$ & $100,45^{b}$ & $811,13^{\mathrm{a}}$ \\
\hline & & Probabilité (5\%) & 0,176 & $\mathbf{0 , 0 0 2}$ & 0,041 \\
\hline & \multirow{4}{*}{$20-40 \mathrm{~cm}$} & Sols sous jachère & $296,23^{a}$ & $116,23^{b}$ & $587,53^{a}$ \\
\hline & & Sols sous culture attelée & $381,67^{\mathrm{a}}$ & $168,40^{\mathrm{a}}$ & $449,93^{\mathrm{a}}$ \\
\hline & & Sols sous culture motorisée & $235,07^{\mathrm{a}}$ & $114,30^{b}$ & $650,63^{a}$ \\
\hline & & Probabilité (5\%) & $\mathbf{0 , 2 8 9}$ & $\mathbf{0 , 0 3 9}$ & $\mathbf{0 , 2 0 7}$ \\
\hline
\end{tabular}

Les valeurs suivies de la même lettre dans chaque colonne ne sont pas statistiquement différentes au seuil de probabilité 5\% selon le test de Fisher. 
Tableau 2 : Bases échangeables et capacité d'échange cationique des sols ferrugineux et des sols ferrallitiques.

\begin{tabular}{|c|c|c|c|c|c|c|c|c|}
\hline \multirow{2}{*}{ Types de sol } & \multirow{2}{*}{ Couches } & \multirow{2}{*}{$\begin{array}{l}\text { Modes d'exploitation des } \\
\text { terres }\end{array}$} & $\mathrm{Ca}^{2+}$ & $\mathrm{Mg}^{2+}$ & $\mathbf{K}^{+}$ & $\mathrm{Na}^{+}$ & SBE & CEC \\
\hline & & & \multicolumn{6}{|c|}{$\mathrm{cmol}^{+} \mathrm{kg}^{-1}$} \\
\hline \multirow{10}{*}{$\begin{array}{l}\text { Ferrugineux } \\
\text { (site de } \\
\text { Dohoun) }\end{array}$} & \multirow{5}{*}{$0-20 \mathrm{~cm}$} & Sols sous jachère & $7,45^{\mathrm{a}}$ & $1,45^{\mathrm{a}}$ & $0,66^{\mathrm{a}}$ & $0,05^{\mathrm{a}}$ & $9,61^{a}$ & $14,11^{\mathrm{a}}$ \\
\hline & & Sols sous culture attelée & $4,59^{b}$ & $1,34^{\mathrm{a}}$ & $0,42^{\mathrm{a}}$ & $0,05^{\mathrm{a}}$ & $6,61^{\mathrm{b}}$ & $10,60^{\mathrm{a}}$ \\
\hline & & Sols sous culture & & & & & & \\
\hline & & motorisée & $2,13^{\mathrm{c}}$ & $0,64^{b}$ & $0,38^{\mathrm{b}}$ & $0,04^{\mathrm{a}}$ & $3,19^{\mathrm{c}}$ & $5,46^{\mathrm{b}}$ \\
\hline & & Probabilité (5\%) & 0,001 & $\mathbf{0 , 0 3 7}$ & 0,147 & 0,634 & $\mathbf{0 , 0 0 1}$ & 0,006 \\
\hline & \multirow{5}{*}{$20-40 \mathrm{~cm}$} & Sols sous jachère & $6,63^{a}$ & $1,41^{\mathrm{a}}$ & $0,52^{a}$ & $0,05^{\mathrm{a}}$ & $8,61^{\mathrm{a}}$ & $11,79^{\mathrm{a}}$ \\
\hline & & Sols sous culture attelée & $3,55^{\mathrm{b}}$ & $0,87^{\mathrm{a}}$ & $0,35^{\mathrm{a}}$ & $0,04^{\mathrm{a}}$ & $4,83^{b}$ & $8,43^{\mathrm{a}}$ \\
\hline & & Sols sous culture & & & & & & \\
\hline & & motorisée & $1,66^{\mathrm{c}}$ & $0,72^{a}$ & $0,33^{\mathrm{a}}$ & $0,04^{\mathrm{a}}$ & $2,75^{\mathrm{b}}$ & $4,85^{\mathrm{b}}$ \\
\hline & & Probabilité $(5 \%)$ & 0,006 & 0,194 & 0,362 & 0,340 & 0,012 & $\mathbf{0 , 0 3 3}$ \\
\hline \multirow{9}{*}{$\begin{array}{l}\text { Ferrallitiques } \\
\text { (site de Balla) }\end{array}$} & \multirow{4}{*}{$0-20 \mathrm{~cm}$} & Sols sous jachère & $1,48^{\mathrm{a}}$ & $0,56^{\mathrm{a}}$ & $0,11^{\mathrm{b}}$ & $0,025^{b}$ & $2,18^{a}$ & $3,38^{a b}$ \\
\hline & & Sols sous culture attelée & $1,46^{\mathrm{ab}}$ & $0,43^{\mathrm{a}}$ & $0,20^{\mathrm{a}}$ & $\underset{\mathrm{ab}}{0,033}$ & $2,13^{\mathrm{a}}$ & $3,68^{\mathrm{a}}$ \\
\hline & & $\begin{array}{l}\text { Sols sous culture } \\
\text { motorisée }\end{array}$ & $0,85^{\mathrm{b}}$ & $0,41^{\mathrm{a}}$ & $0,13^{a b}$ & $0,037^{\mathrm{a}}$ & $1,42^{\mathrm{a}}$ & $2,36^{\mathrm{b}}$ \\
\hline & & Probabilité (5\%) & $\mathbf{0 , 0 3 6}$ & 0,772 & 0,019 & $\mathbf{0 , 0 3 4}$ & $\mathbf{0 , 1 5}$ & $\mathbf{0 , 0 3 3}$ \\
\hline & \multirow{5}{*}{$20-40 \mathrm{~cm}$} & Sols sous jachère & $1,67^{\mathrm{a}}$ & $0,65^{\mathrm{a}}$ & $0,09^{a}$ & $0,027^{b}$ & $2,44^{\mathrm{a}}$ & $4,54^{\mathrm{a}}$ \\
\hline & & Sols sous culture attelée & $1,32^{a b}$ & $0,68^{a}$ & $0,11^{\mathrm{a}}$ & $0,037^{\mathrm{a}}$ & $2,15^{a b}$ & $3,84^{a b}$ \\
\hline & & Sols sous culture & & & & 0,030 & & \\
\hline & & motorisée & $0,91^{\mathrm{b}}$ & $0,49^{a}$ & $0,11^{\mathrm{a}}$ & & $1,54^{\mathrm{b}}$ & $2,80^{\mathrm{b}}$ \\
\hline & & Probabilité (5\%) & $\mathbf{0 , 0 3 5}$ & 0,451 & $\mathbf{0 , 5 0 6}$ & 0,044 & $\mathbf{0 , 0 2 2}$ & $\mathbf{0 , 0 3 0}$ \\
\hline
\end{tabular}
chaque colonne ne sont pas statistiquement différentes au seuil de probabilité 5\% selon le test de Fisher.

Tableau 3 : pH eau et $\mathrm{pH} \mathrm{KCl}$ des sols ferrugineux et ferrallitiques.

\begin{tabular}{llllll}
\hline \multirow{2}{*}{ Types de sol } & \multirow{2}{*}{ Modes d'exploitation des terres } & \multicolumn{2}{c}{ pH eau } & \multicolumn{2}{c}{ pH KCl } \\
\cline { 3 - 5 } & & $\mathbf{0 - 2 0} \mathbf{~ c m}$ & $\mathbf{2 0 - 4 0} \mathbf{~ c m}$ & $\mathbf{0 - 2 0} \mathbf{~ c m}$ & $\mathbf{2 0 - 4 0} \mathbf{~ c m}$ \\
\hline Ferrugineux & Sols sous jachère & $5,84^{\mathrm{a}}$ & $5,68^{\mathrm{ab}}$ & $4,93^{\mathrm{a}}$ & $4,69^{\mathrm{a}}$ \\
(site de Dohoun) & Sols sous culture attelée & $5,99^{\mathrm{a}}$ & $6,29^{\mathrm{a}}$ & $5,10^{\mathrm{a}}$ & $4,94^{\mathrm{a}}$ \\
& Sols sous culture motorisée & $5,72^{\mathrm{a}}$ & $5,40^{\mathrm{b}}$ & $4,51^{\mathrm{b}}$ & $4,10^{\mathrm{b}}$ \\
& Probabilité (5\%) & $\mathbf{0 , 6 7 4}$ & $\mathbf{0 , 0 3 1}$ & $\mathbf{0 , 0 4 2}$ & $\mathbf{0 , 0 3 1}$ \\
\hline Ferrallitiques & Sols sous jachère & $5,93^{\mathrm{a}}$ & $5,32^{\mathrm{a}}$ & $4,60^{\mathrm{ab}}$ & $3,95^{\mathrm{a}}$ \\
(site de Balla) & Sols sous culture attelée & $5,98^{\mathrm{a}}$ & $5,00^{\mathrm{a}}$ & $4,82^{\mathrm{a}}$ & $3,93^{\mathrm{a}}$ \\
& Sols sous culture motorisée & $5,17^{\mathrm{b}}$ & $4,80^{\mathrm{a}}$ & $4,14^{\mathrm{b}}$ & $3,99^{\mathrm{a}}$ \\
& Probabilité (5\%) & $\mathbf{0 , 0 0 6}$ & $\mathbf{0 , 2 9 6}$ & $\mathbf{0 , 0 3 5}$ & $\mathbf{0 , 9 6 5}$ \\
\hline
\end{tabular}

Les valeurs suivies de la même lettre dans chaque colonne ne sont pas statistiquement différentes au seuil de probabilité $5 \%$ selon le test de Fisher.

Tableau 4 : Teneurs en aluminium échangeable des sols sur 0-40 cm.

\begin{tabular}{|c|c|c|c|}
\hline \multirow{2}{*}{\multicolumn{2}{|c|}{ Modes d'exploitation des terres }} & $\begin{array}{l}\text { Sols ferrugineux } \\
\text { (site de Dohoun) }\end{array}$ & $\begin{array}{l}\text { Sols ferrallitiques } \\
\text { (site de Balla) }\end{array}$ \\
\hline & & \multicolumn{2}{|c|}{$\mathrm{Al}^{3+}\left(\mathrm{cmol}^{+} \mathrm{kg}^{-1}\right)$} \\
\hline \multicolumn{2}{|l|}{ Sols sous jachère } & 0,050 & 0,050 \\
\hline \multicolumn{2}{|c|}{ Sols sous culture attelée } & 0,058 & 0,081 \\
\hline \multicolumn{2}{|c|}{ Sols sous culture motorisée } & 0,050 & 0,050 \\
\hline \multicolumn{2}{|c|}{ Moyennes (Type de sol) } & 0,059 & 0,063 \\
\hline \multirow{3}{*}{ Probabilité (5\%) } & Types de sol & \multicolumn{2}{|c|}{0,728 (ns) } \\
\hline & Modes d'exploitation des terres & \multicolumn{2}{|c|}{$0,726(\mathrm{~ns})$} \\
\hline & Types de sols x Modes d'exploitation des terres & \multicolumn{2}{|c|}{$0,084(\mathrm{~ns})$} \\
\hline
\end{tabular}

ns = non significatif au seuil de probabilité 5\% selon le test de Fisher. 


\section{C $\left(\mathrm{g} \mathrm{kg}^{-1}\right)$}

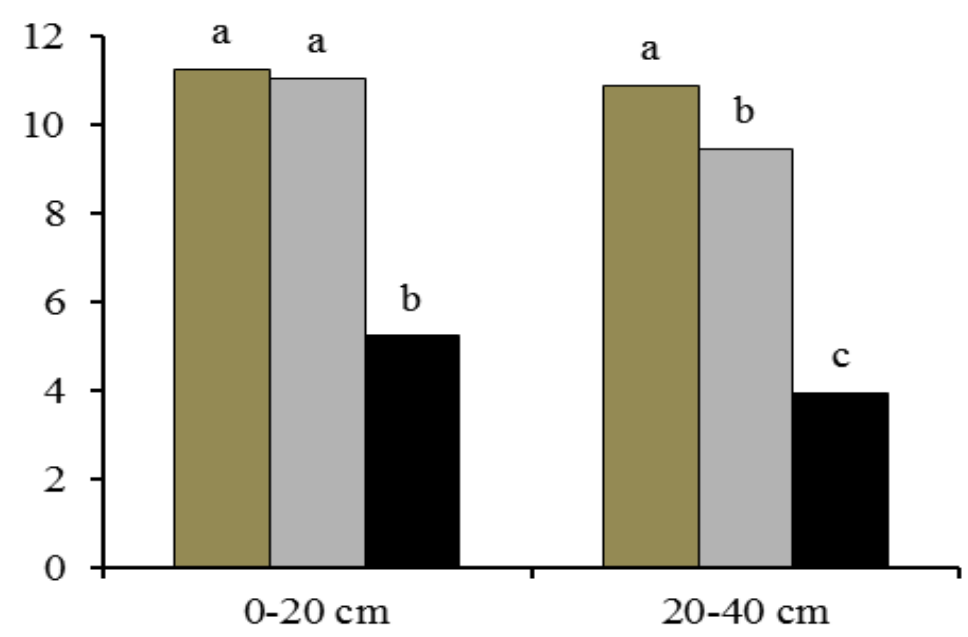

a) sols ferrugineux (site de Dohoun)

sols sous jachère naturelle

$\square$ sols sous culture attelée

- sols sous culture motorisée

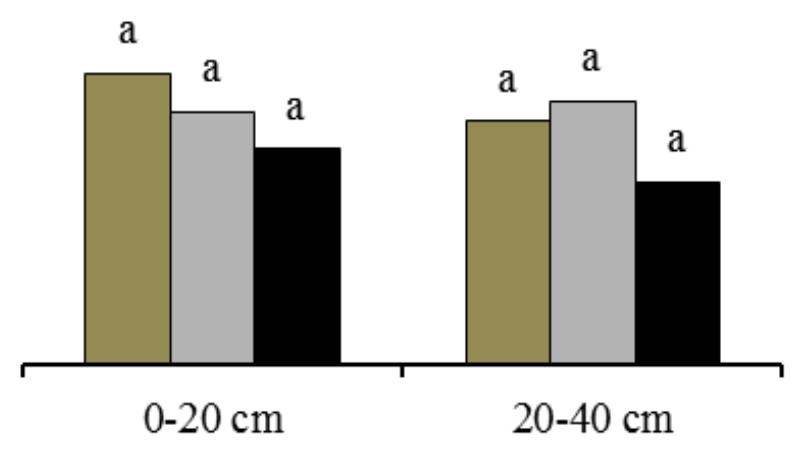

b) Sols ferrallitiques (site de Balla)

Figure 1 : Teneurs en carbone des sols ferrugineux (a) et des sols ferrallitiques (b). Les histogrammes suivis de la même lettre ne sont pas statistiquement différents au seuil de probabilité 5\% selon le test de Fisher. 


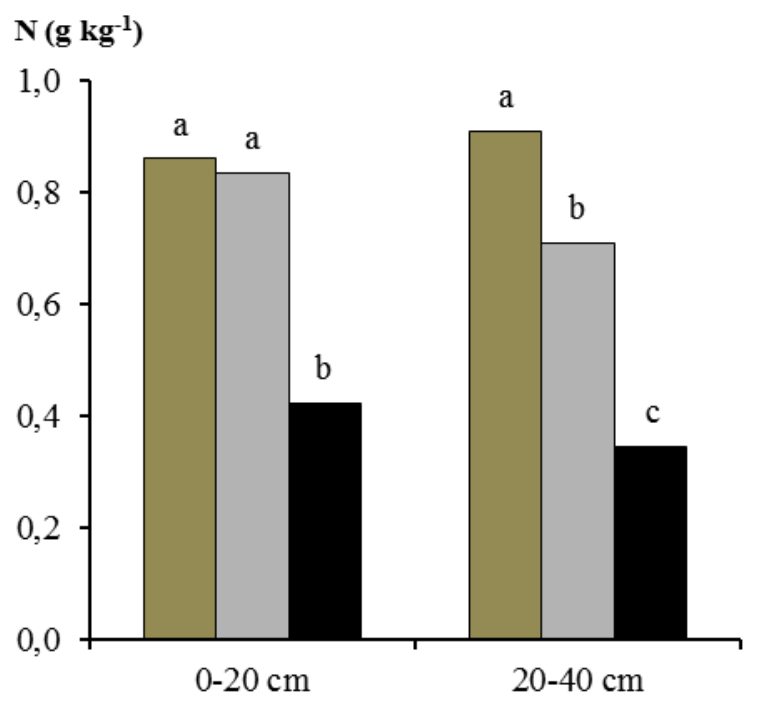

a) sols ferrugineux (site de Dohoun)

$$
\begin{aligned}
& \square \text { sols sous jachère naturelle } \\
& \square \text { sols sous culture attelée } \\
& \square \text { sols sous culture motorisée }
\end{aligned}
$$

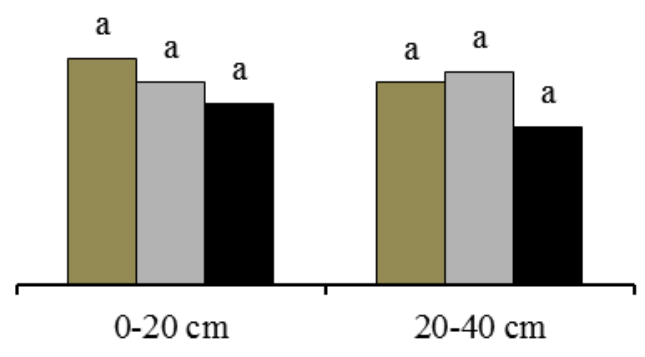

b) Sols ferrallitiques (site de Balla)

Figure 2 : Teneurs en azote des sols ferrugineux (a) et des sols ferrallitiques (b). Les histogrammes suivis de la même lettre ne sont pas statistiquement différentes au seuil de probabilité 5\% selon le test de Fisher.

\section{DISCUSSION}

La composition granulométrique des sols ferrugineux et des sols ferrallitiques montre qu'ils sont pauvres en argile, or, c'est pourtant elle qui conditionne la fixation des éléments minéraux sur le complexe adsorbant. La forte proportion de sable trouvée dans l'horizon superficiel des sols cultivés serait liée aux effets déstructurants du sol provoqués par le labour, notamment celui réalisé au tracteur (Ouattara et al., 2006 ; Lalsaga, 2007). La culture motorisée a entraîné, en surface des sols ferrugineux et des sols ferrallitiques, des pertes d'argiles, dont la fraction fine assure, pour l'essentiel, la régulation des phénomènes physico-chimiques contrôlant l'acidification du sol. 
L'appauvrissement en argile de la partie supérieure des sols cultivés se justifierait, d'après Son et al. (2004), par le lessivage des argiles et leur entraînement en profondeur, plus accentué sous culture motorisée que sous culture attelée. Ceci diminue, non seulement la teneur en colloïdes minéraux, mais aussi celle des colloïdes organiques des sols (Yemefack et al., 2004) qui contrôlent l'acidité par les charges électriques présentes à la surface de ces constituants argileux et organiques. Par rapport à la jachère, l'exploitation des terres, surtout sous culture motorisée, a eu pour conséquence, une importante perte d'argile, qui affecte le complexe adsorbant et expose les sols à l'acidification.

Dans le Tableau 2, les résultats ont révélé de faibles teneurs en carbone sur ces sols cultivés ou sous jachère, ce qui confirme la pauvreté en matière organique de la plupart des sols du Burkina Faso (Sawadogo et al., 2008). Les faibles stocks de matière organique dans ces sols, les prédisposeraient à une acidification et à une dégradation rapide (Brady et Weil, 2008; Pallo et al., 2009). Les faibles teneurs en carbone observées, y compris au niveau des sols sous jachère, dénotent que les jachères naturelles de 10 à 15 ans, servant souvent de zones de pâturage, n'ont pas permis de régénérer la fertilité des sols, notamment l'amélioration du niveau de matière organique, susceptible d'atténuer le processus d'acidification du sol (Abbadie et al., 2000). A cause de la faible régénération de la fertilité par les jachères naturelles dans cette zone cotonnière du Burkina Faso, Somé et al. (2007) ont recommandé d'introduire des espèces améliorantes à base d'Andropogon $s p$ dans les jachères de courte durée. La baisse des teneurs en carbone et en azote, provoquée par la mise en culture continue de ces sols, serait imputable d'une part, à l'insuffisance, voire l'absence d'apport de fumure organique, et d'autre part au travail du sol, qui conduit à une perte de carbone par la minéralisation et par l'érosion hydrique (Traoré et al., 2007 ; Pouya et al., 2013). La baisse des teneurs en carbone, plus accentuée sous culture motorisée que sous culture attelée, se justifie, d'après Ouattara et al. (2006), par l'étroite dépendance entre la baisse du taux de matière organique du sol et son intensité culturale, le rendant ainsi vulnérable à l'acidification.

Alors que les teneurs en $\mathrm{Ca}^{2+}$ et $\mathrm{Mg}^{2+}$ des sols ferrugineux étaient jugées satisfaisantes sous jachère et sous culture attelée, la culture motorisée a conduit à des teneurs proches du seuil de déficience (Landon, 1991; Oorts et al., 2003). La pauvreté en bases échangeables observée dans les sols ferrallitiques, même sous jachère, semble confirmer que le processus de restauration de la fertilité chimique, notamment l'amélioration du complexe adsorbant par le seul effet de la jachère naturelle, est souvent très long (Somé et al., 2007). Les réserves en bases échangeables, liées à la nature du sol, étaient plus fortes dans les sols ferrugineux que dans les sols ferrallitiques déficients en $\mathrm{Ca}^{2+}$ et $\mathrm{Mg}^{2+}$, et plus exposés à l'acidification (Landon, 1991 ; Mbonigaba Muhinda et al., 2009). Les baisses spectaculaires de la CEC dans les sols ferrugineux et ferrallitiques sous culture motorisée, pourraient être attribuées à un lessivage de l'argile, en relation avec les labours réalisés chaque année au tracteur (Yemefack et al., 2004 ; Ouattara, 2009) et à l'emploi quasi exclusif d'engrais minéraux acidifiants (Pernes-Debuyser et Tessier, 2002; Schroder et al., 2012). La faible CEC des sols ferrallitiques serait imputable, d'après Mbonigaba Muhinda et al. (2009), à leur pauvreté en matière organique, ce qui les expose davantage à l'acidification, comparativement aux sols ferrugineux. Sur ces sols relativement fragiles, l'adoption de techniques appropriées de travail du sol au tracteur s'impose. Cette disposition demeure tout aussi valable sous culture attelée, car, selon Ouattara (2009), une réduction des fréquences de labour permet d'améliorer les propriétés physiques et chimiques du sol, notamment, la CEC. Les diverses pertes de cations échangeables, de matière organique et le lessivage de l'argile, qui sont supposées 
être la conséquence de la culture motorisée, entraînent la dégradation du sol et son acidification.

Les valeurs de $\mathrm{pH}$ indiquent d'après Brady et Weil (2008) que les sols ferrugineux étaient légèrement acides et les sols ferrallitiques fortement acides, ce qui confirme que l'expression de l'acidité dépend de la nature du sol (Kaitibie et al., 2002). La ferrallitisation, qui débute par une hydrolyse neutre, puis une acidification, et qui, de plus, est à l'origine de la formation et de l'évolution des sols ferrallitiques, explique leur acidité plus forte que celle des sols ferrugineux. L'acidification de ces sols, plus prononcée en surface, serait liée à l'utilisation d'engrais minéraux acidifiants et à la fragilisation du sol par les labours répétés au tracteur, favorisant le lessivage du calcium et du magnésium du complexe (Pernes-Dubuyer et Tessier, 2002; Bauer et al., 2012). Yemefack et al. (2004) justifient l'acidification souvent prononcée dans les sols sous jachère, par la libération d'acides organiques. Les valeurs de $\mathrm{pH}$ eau, inférieures au seuil de 5,5 défini par Brady et Weil (2008), pourraient être un facteur limitant pour l'alimentation des plantes. L'aluminium sous forme échangeable, dans ces sols, pourrait provoquer, sur les cultures, des problèmes de toxicité aluminique, surtout dans les sols ferrallitiques, qui sont fortement acides (Brady et Weil, 2008). L'aluminium échangeable, qui résulte de la dégradation des argiles, peut être complexé par la matière organique pour donner une forme non soluble dans la solution du sol (Oorts et al., 2003; Logan et al., 2008; Zołotajkin et al., 2011). De ce fait, un apport de matière organique pourrait être bénéfique pour assurer une productivité durable sur les sols ferrugineux et ferrallitiques, qui subissent une dégradation, suite à leur mise en culture.

\section{Conclusion}

L'étude menée a montré que l'exploitation des terres, surtout en culture motorisée, se traduisait par une baisse des teneurs en argile, en carbone, en azote, une lixiviation des bases échangeables, ainsi qu'une baisse de la capacité d'échange cationique, rendant ainsi ces sols vulnérables à l'acidification, qui est atténuée sous la jachère. Cette dégradation $\mathrm{du}$ sol, plus accentuée en culture motorisée qu'en culture attelée, est d'autant marquée que les sols sont fragiles, pauvres en argile et plus sensibles à l'acidification, comme les sols ferrugineux et ferrallitiques étudiés, fréquemment rencontrés dans la zone cotonnière du Burkina Faso. La pauvreté en carbone des sols, accentuée par la présence d'aluminium échangeable dans ces sols, suggère la nécessité de privilégier des techniques adéquates de travail du sol, d'étudier l'impact des engrais azotés, largement utilisés en zone cotonnière, et de procéder à des amendements appropriés pour maintenir durablement la productivité dans ce système de culture.

\section{REMERCIEMENTS}

Les auteurs remercient l'Association Interprofessionnelle du Coton du Burkina Faso (AICB) en particulier la Société Burkinabè des Fibres Textiles (SOFITEX) pour son appui financier et matériel dans la réalisation de cette étude. Ils remercient également tous les techniciens du Programme Coton de l'Institut de l'Environnement et de Recherches Agricoles (IN.E.R.A) pour leur contribution à la réalisation de cette étude.

\section{REFERENCES}

Abbadie L, Lata JC, Tavernier V. 2000. Impact des graminées sur une ressource rare : l'azote. In La Jachère en Afrique Tropicale, Floret Ch, Pontanier R (eds). John Libbey Eurotext, Paris, 189-193.

Agoumé V, Birang AM. 2009. Impact of landuse systems on some physical and chemical soil properties of an oxisol in the humid forest zone of southern Cameroon. Tropicultura, 27(1): 15-20.

Bauer PJ, Szogi AA, Novak JM, Vanotti MB. 2012. Phosphorus recovered from swine wastewater as a fertilizer for cotton 
grown with conservation tillage. Journal of Cotton Science, 16(2): 97-104.

Barro A, Zougmoré R, Sédogo MP. 2009. Evaluation de la faisabilité de trois types de travail du sol: application du modèle Sarra dans le Plateau central au Burkina Faso. Sécheresse, 20(4): 338-345.

Brady NC, Weil RR. 2008. The Nature and Properties of Soils. 14 ed., PearsonPrentice Hall, Upper Saddle River: NJ; $990 \mathrm{p}$.

Bunasols. 1987. Méthodes d'analyse physique et chimique des eaux et du sol. Document technique $\mathrm{n}^{\circ} 3$. Ouagadougou, Burkina Faso, 159 p.

CPCS. 1967. Classification des sols. Travaux de la Commission de Pédologie et de la Cartographie des sols, CPCS, 96 p.

FAO. 2006. World reference base for soil resources 2006. A framework for international classification, correlation and communication. 2nd edition. World Soil Resources Reports No. 103. FAO, Rome, 145 p.

Hauchart V. 2006. Le coton dans le Mouhoun (Burkina Faso), un facteur de modernisation agricole : perspectives de développement? Agricultures, 15(3): 285-291.

Kaitibie S, Epplin FM, Krenzer EA, Zhang H. 2002. Economics of lime and phosphorus application for dual-purpose winter wheat production in low-pH soils. Soil Sci. Am. J., 94: 1145-1145.

Koulibaly B, Traoré O, Dakuo D, Zombré PN, Bondé D. 2010. Effets de la gestion des résidus de récolte sur les rendements et les bilans culturaux d'une rotation cotonnier-maïs-sorgho au Burkina Faso. Tropicultura, 28(3): 184-189.

Koulibaly B. 2011. Caractérisation de l'acidification des sols et gestion de la fertilité des agrosystèmes cotonniers au Burkina Faso. Thèse de doctorat unique : Université de Ouagadougou, Laboratoire de biologie et écologie végétales (Burkina Faso), $155 \mathrm{p}$.
Lalsaga R. 2007. Caractérisation de trois types de sols en zone cotonnière ouest du Burkina Faso : impacts des systèmes de culture sur l'acidité des sols. Mémoire de DEA en Sciences appliquées de la terre, de l'eau et des sols. Option pédologie, Université de Ouagadougou, 57 p.

Landon JR. 1991. Booker Tropical Soil Manual. A Handbook for Soil Survey and Agricultural Land Evaluation in the Tropics and Subtropics. Oxon, Booker Tate Limited; Harlow, Essex: UK, Longman; $474 \mathrm{p}$.

Logan AB, Floate MJS, Ironside AD. 2008. Determination of exchangeable acidity and exchangeable aluminum in hill soils part 1 exchangeable acidity. Communications in Soil Science and Plant Analysis, 16(3): 301-308.

Mbonigaba Muhinda JJ, Nzeyimana I, Bucagu C, Culot M. 2009. Caractérisation physique, chimique et microbiologique de trois sols acides tropicaux du Rwanda sous jachères naturelles et contraintes à leur productivité. Biotechnol. Agron. Soc. Environ., 13(4): 545-558.

Mbétid-Bessane E. 2010. Investissement en culture attelée et amélioration de la rentabilité de la culture cotonnière en Centrafrique. Tropicultura, 28(3): 178183.

McLean EO. 1982. Soil $\mathrm{pH}$ and lime requirement. In Methods of soil analysis. Agronomy Monograph $N^{\circ} 9$ (Part II. 2nd edn). Millet RH, Keeney DR (eds). Madison: WI; 199-223.

Oorts K, Vanluwe B, Merckx R. 2003. Cation exchange capacity of organic matter fractions in a ferric lixisol with different organic matter inputs. Agric. Ecosyst. Environ., 100: 161-171.

Ouattara B. 2009. Analyse-diagnostic du statut organique et de l'état structural des sols des agrosystèmes cotonniers de l'Ouest du Burkina Faso (terroir de Bondoukui). Thèse de doctorat d'Etat: Université Polytechnique de BoboDioulasso (Burkina Faso), 250 p. 
Ouattara B, Ouattara K, Serpentié G, Mando A, Sédogo MP, Bationo A. 2006. Intensity cultivation induced effects on soil organic carbon dynamic in the western cotton area of Burkina Faso. Nutr. Cycl. Agroecosyst, 76: 331-339.

Pallo FJP, Sawadogo N, Zombré NP, Sédogo PM. 2009. Statut de la matière organique des sols de la zone nord soudanienne au Burkina Faso. Biotechnol. Agron. Soc. Environ., 13(1): 139-142.

Pernes-Debuyser A, Tessier D. 2002. Influence de matières fertilisantes sur les propriétés des sols. Cas des 42 parcelles de l'INRA à Versailles. Etude et Gestion des Sols, 9(3): 177-186.

Pouya MB., Bonzi M, Gnankambary Z, Koulibaly B, Ouédraogo I, Ouédraogo JS, Sédogo PM. 2013. Perception paysanne et impact agro-pédologique du niveau de mécanisation agricole dans les zones cotonnières Centre et Ouest du Burkina Faso. Int. J. Biol. Chem. Sci., 7(2): 489506.

Sawadogo H, Bock L, Lacroix D, Zombré NP. 2008. Restauration des sols dégradés à l'aide du zaï et du compost dans le Yatenga (Burkina Faso). Biotechnol. Agron. Soc. Environ., 12(3): 279-290.

Somé NA, Traoré K, Traoré O, Tassembedo M. 2007. Potentiel des jachères artificielles à Andropogon spp. dans l'amélioration des propriétés chimiques et biologiques des sols en zone soudanienne (Burkina Faso). Biotechnol. Agron. Soc. Environ., 11(3): 245-252.

Son G, Badraoui M, Kambire F. 2004. Influence de la pluviométrie sur l'efficience en rendement coton-graine de cinq systèmes techniques de préparation du sol dans l'Ouest du Burkina Faso. Communication au FRSIT 2004, Ouagadougou, $13 \mathrm{p}$.

Traoré O, Somé NA, Traoré K, Somda K. 2007. Effect of land use change on some important soil properties in cotton-based farming system in Burkina Faso. Int. J. Biol. Chem. Sci., 1(1): 7-14.

Walkley A, Black JA. 1934. An examination of the Detjareff method for determining soil organic matter and a proposed modification of the chromatic acid titration method. Soil Science, 37: 29-38.

Yemefack M, Nounamo L, Njomgang R, Bilong P. 2004. Influence des pratiques agricoles sur la teneur en argile et autres propriétés agronomiques d'un sol ferrallitique au sud du Cameroun. Tropicultura, 22(1): 3-10.

Zołotajkin M, Ciba J, Kluczka J, Monika Skwira M, Smoliński A. 2011. Exchangeable and bioavailable aluminium in the mountain forest soil of Barania Góra Range (Silesian Beskids, Poland). Water Air Soil Pollut., 216(1-4): 571-580. 